\title{
La esfera nocturna de la historia: esplendor y miseria de la llustración
}

\author{
The nocturnal sphere of history: splendor and misery of the Enlightenment
}

Javier Corona Fernández

Universidad de Guanajuato - México

Guanajuato, México

cofeja@ugto.mx

\section{RESUMEN}

El artículo actualiza el problema que la Escuela de Frankfurt afrontó respecto al análisis de las condiciones que configuran el entorno técnico y natural en las sociedades industrializadas y, con ello, las posibilidades reales para hacer de la vida en la Tierra tanto un infierno de destructividad y desolación como todo lo contrario. Mas la expectativa de acceder a un estado de humanidad y a un mundo circundante distinto no puede ser factible si se permanece atado a la ideología del progreso. Lo que se requiere es una ruptura en el continuo histórico: rechazar la violencia y pronunciarse a favor de la dignificación del ser humano. La posición de discurso en la que se inscribe este escrito es la teoría crítica de la sociedad, que deduce sus enunciados acerca de las situaciones reales a partir de conceptos universales básicos, pero no sólo en cuanto a su necesidad en sentido lógico, sino a su necesidad concreta. La construcción del acontecer histórico es visto por la teoría crítica como el producto de un mecanismo económico que contiene ya la posibilidad de protestar contra ese orden y, con el despliegue de la subjetividad crítica, permitir que las acciones de los hombres no respondan a un ciego dominio, sino que resulten de sus propias decisiones. Para romper ese dominio inercial y conducirse con autonomía, la humanidad debe poner a la vista y ser consciente de lo que acaece en la esfera nocturna de la historia, caracterizada por la destrucción humana, el hambre, el tráfico de personas, la nueva esclavitud y la auto aniquilación.

Palabras clave: progreso; continuo histórico; teoría crítica.

\section{ABSTRACT}

This article updates the problem that the Frankfurt School faced regarding the analysis of the conditions that configure the technical and natural environment in industrialized societies and, with it, the real possibilities to make life on Earth at once a hell of destructiveness and desolation as the opposite. But the expectation of accessing a state of humanity and a different surrounding world cannot be possible if one remains tied to the ideology of progress. What is required is a break in the historical continuum: reject violence and speak out in favor of the dignity of the human being. The position of discourse in which this writing is inscribed is the critical theory of society, which deduces its statements about real situations from basic universal concepts, but not only in terms of their necessity in a logical sense, but also their concrete necessity. The construction of historical events is seen by critical theory as the product of an economic mechanism that already contains the possibility of protesting against that order and, with the unfolding of critical subjectivity, allowing the actions of men not to respond to a blind domain, but to result from their own decisions. To break this inertial dominance and conduct itself autonomously, humanity must expose and be aware of what happens in the nocturnal sphere of history, characterized by human destruction, hunger, human trafficking, the new slavery and self-annihilation.

Keywords: progress; historical continuum; critical theory. 


\title{
1. INTRODUCCIÓN
}

El presente ensayo parte de una idea expresada en el apartado Interés por el cuerpo, en la sección titulada "Apuntes y esbozos", casi al final de Dialéctica de la Ilustración (Adorno y Horkheimer, 1998, p. 280). La importancia y actualidad del tema radica en plantear una reflexión sobre las formas cada vez más exacerbadas de violencia en la sociedad, tópico en el que está presente la obra de Freud bajo la hipótesis de que la civilización, en su desarrollo, es un proceso de intensificación del sentimiento de culpa, propiciado por la tensión que subyace a las inclinaciones hacia el amor y la violencia que llevan finalmente a la muerte, pulsiones que atraviesan la vida individual y colectiva en todos sus espacios y manifestaciones. La propuesta de Freud es que tal sentimiento de culpa surge en las hordas primitivas, en los orígenes de las sociedades humanas, y cada generación carga con el peso de esa maldición, que es una carga culpable por ser, asimismo, una transgresión. En efecto, según Freud, en la horda primitiva existe un momento de malestar, de preocupación e incertidumbre que toma curso cuando un individuo (el padre), como líder, se impone a los otros a fin de garantizar la cohesión de la horda, la que es sometida y a la que se le impone una serie de restricciones y compromisos, entre ellos el deber del trabajo para satisfacer las necesidades del grupo, situación que en cada generación se refuerza hasta ahondar la huella represiva de la cultura. "La mayoría de los hombres siempre ha trabajado bajo la dirección y a las órdenes de una minoría, y esta dependencia siempre se tradujo en una existencia material más penosa" (Horkheimer, 1998, p. 96).

Atada a esta cadena, la sociedad contemporánea tiene en sus archivos ser la causante de la descomposición más acendrada merced al excluyente sistema económico que, de la mano del gobierno, ha impulsado la escalada de sometimiento y destructividad, utilizando sin reparos todo el potencial armamentista de alta tecnología que inició con la prueba en Alamogordo en 1945 y cuya amenaza hasta la fecha no ha parado. En pleno siglo XXI se siguen efectuando ensayos nucleares para la fabricación de "nuevas armas estratégicas". Resulta evidente que la sociedad actual no tiene la opción de elegir entre violencia o no violencia, sino entre distintos tipos de ésta (Mcbride, 2013, p. 9). Paralelamente, la proliferación de sentimientos apocalípticos se ha incrementado desde que hubo conciencia del riesgo real de desaparecer como especie debido a la devastación y a las formas de terror que pueden ejercerse, no sólo por medio de las armas de destrucción masiva, sino por la situación límite a la que ha conducido la barbarie ejercida contra los entornos naturales en aras de un incremento de la riqueza y la productividad a un ritmo demencial.

\begin{abstract}
El mundo ha entrado en un período en el que el peligro es alto y el margen de error, bajo. Si los responsables de la toma de decisiones continúan sin actuar, los ciudadanos de todo el mundo deberían hacerse eco de las palabras de la activista climática Greta Thunberg y preguntar: “¿Cómo os atrevéis?”. Con estas palabras, Rachel Bronson, presidenta del Boletín de Científicos Atómicos adelantaba la decisión de este grupo de expertos: la humanidad está a solo 100 segundos del apocalipsis, lo más cerca que ha estado nunca. Como cada año, el boletín ha dado a conocer su diagnóstico sobre el riesgo de exterminarse que afronta la humanidad. Para medirlo, este grupo de expertos de primer nivel con 13 premios Nobel en sus filas, creó un reloj simbólico, el Reloj del Apocalipsis (Doomsday Clock), que muestra los minutos que nos quedan hasta la medianoche, es decir, el fin del mundo. Desde 2018 las manecillas estaban colocadas a las 23.58, a dos minutos del final, que es lo más cerca que el reloj había estado de la medianoche en sus 73 años de historia. A esa misma hora, a 120 segundos, estuvo en 1953, cuando las armas termonucleares soviéticas y estadounidenses se ponían a prueba en plena carrera armamentística. Ahora está todavía más cerca del fin (Salas, 2020).
\end{abstract}

Es evidente que, como formación histórico-social, la sociedad contemporánea dio término a la imagen decimonónica de la vida y de la historia y ha visto emerger, además del orden tecnológico, un nuevo campo de investigación al incursionar en las diversas capas de la vida anímica de los seres humanos, en su subjetividad y en las identidades que los han amoldado. Con ello vino el planteamiento acerca de las relaciones conflictivas del individuo con la sociedad y la consideración sobre las formas diversas en que el poder se ejerce, sus mecanismos de dominio y control de la existencia al interior de una sociedad que ha supuesto la eliminación del sortilegio de fuerzas mágicas y religiosas anteriores a la explicación mecanicista del mundo, pero que asimismo ha acrecentado su capacidad de manipulación acudiendo a toda suerte de embelesos para consumar, mediante la seducción, el dominio pleno de las expectativas individuales en una época política y moralmente fracturada, que, en aras de la producción como principio 
único, ha convertido en basurero su entorno.

\begin{abstract}
En la última década, en la que la emergencia climática ha empezado a mostrar sus efectos, la manecilla del reloj no ha dejado de acercarse a la medianoche. Los cinco años en los que se ha registrado una mayor temperatura del planeta han sucedido después de 2015. Además, cada año se van incorporando lo que los expertos llaman riesgos existenciales: factores que ponen en peligro la continuidad de la humanidad tal y como la conocemos. La inteligencia artificial, la biotecnología o las nuevas pandemias son amenazas que aumentan la presión sobre el Reloj del Apocalipsis, sumándose al peligro atómico original y la emergencia climática (Salas, 2020).
\end{abstract}

Para la teoría crítica de la sociedad, en este nuevo escenario cobra especial interés la conducta de los sujetos en el espacio político, acotado por el cerco invulnerable de las instituciones, aunque extendido en los modos de opresión cada vez más depurados que consuman un sutil control de la conciencia. Al incursionar en estos problemas, la teoría crítica ha permitido aprehender los rasgos de una realidad marcada por la destructividad en la entraña misma de un sistema de explotación que determina los rasgos en los que la subjetividad individual queda maniatada por los dispositivos de opresión.

El esclarecimiento de esta problemática tiene, en la obra de Marx y Freud respectivamente —con la influencia y las consecuencias que sus investigaciones tuvieron en el pensamiento crítico de Adorno, Horkheimer, Marcuse y Foucault-, los signos para pensar en qué términos se puede vislumbrar la realidad individual y colectiva bajo el perfil de un poder opresivo y controlador, el cual extiende su dominio en los más recónditos resquicios de la vida. El pulso de esta realidad ha sido tomado por el pensamiento de estos autores que, desnudando las ciencias y los saberes distintos que se ocupan de la condición humana, puso a la vista no sólo las ideologías y discursos embozados o abiertamente despóticos, sino las instituciones y prácticas de dominación que han obliterado a individuos y comunidades.

Dentro de esta elucidación es factible indicar la transformación de un componente central que marcó la pauta para exponer las características en que hoy día se ejerce el poder. En efecto, si todavía con el paso del siglo XIX al XX el Estado era el referente principal en la articulación de las estructuras de dominio, ahora, desde las postrimerías de la centuria pasada, el Estado no juega ya el mismo papel que tuvo hasta la Segunda Guerra Mundial, pues a partir de entonces el poder se ha depurado en la manera en que se ejerce y vincula en redes y sistemas, detonando su capacidad de sujeción no sólo en una instancia identificable como podría ser el Estado. Frente a tal figura, la filosofía crítica estableció su nueva posición reflexiva: el objetivo está en analizar los retículos de la vida cotidiana, las estrategias, las situaciones emergentes en las cuales los miembros de la sociedad —bajo presión violenta o incitación placentera- activan y dan significado a sus identidades y propósitos. Lo revelador de dicho emplazamiento es que la subjetividad puede ser, incluso, autorreflexiva y vislumbrar tentativas por desmarcarse de las estrategias de dominación que le sujetan. Si en el plano social han fracasado las instancias que representan lo que otrora se consideró como interés legítimo de la humanidad; si las instituciones, los sindicatos o las corporaciones no muestran ningún compromiso con sus agremiados, y los partidos de oposición se han adaptado a la dinámica lucrativa de la "democracia", ¿qué se puede hacer desde el ámbito de la individualidad consciente?, ¿cómo actuar políticamente en un espacio tan acotado?

Obviamente no puede pretenderse una respuesta concluyente, sobre todo porque las organizaciones políticas que se han adueñado de la esfera pública tienen numerosas dificultades para señalar una dirección convocante. A este respecto, la Teoría crítica se planteó la importancia que una educación política podría tener yendo a lo más íntimo de las relaciones personales y sus tentativas de solidaridad, lo cual implica hablar de experiencias no mediatizadas y opuestas a la hegemonía del mercado (Marcuse, 1981, pp. 11-12). Para tal propósito es preciso convocar otros impulsos, articulados en pequeños proyectos que puedan ser, en alguna medida, interruptores del continuum histórico. Lo inactual o intempestivo de la teoría crítica consiste en mantener aún como posibilidad real el arribo a una sociedad humana racional, que no se define por el instinto de destrucción, sino que, a contracorriente de esa barbarie generalizada, se destaca por formas de convivencia alternativas. Esta esperanza no es una pretensión ingenua, sino un precepto viable ante el dominio corporal de la existencia que ejerce el biopoder, lo que significa impulsar la tarea de erotizar la sociedad para eludir una norma aplastante que va a la esencia misma de la vida y maniata todo tipo de conciencia, pero que aún no ha podido desarticular el carácter creativo que subyace en toda dimensión erótica de la vida. Adorno lo explica en La educación después de Auschwitz en los términos 
siguientes: "La educación en general carecería absolutamente de sentido si no fuese educación para una autorreflexión crítica” (1993, p.82).

Por su parte, los objetivos y alcances de este artículo se limitan a orientar la reflexión sobre las formas en que se articula el dominio en la sociedad y, eventualmente, identificar lo que la Escuela de Frankfurt llamó "la esfera nocturna de la historia". Para dicho propósito, la metodología empleada es la que proporciona la teoría crítica de la sociedad que, en su totalidad, plantea un único juicio de existencia desarrollado:

Este juicio afirma, dicho en términos generales, que la forma básica de la economía de mercancías históricamente dada, sobre la cual reposa la historia moderna, encierra en sí misma los antagonismos internos y externos de la época, los renueva constantemente de una manera agudizada, y que, tras un período de ascenso, de desarrollo de fuerzas humanas, de emancipación del individuo, tras una fabulosa expansión del poder del hombre sobre la naturaleza, termina impidiendo la continuación de ese desarrollo y lleva a la humanidad hacia una nueva barbarie (Horkheimer, 1998, p. 257).

La teoría crítica continúa siendo el emplazamiento teórico que marca una vía de acceso a los más urgentes problemas del género humano en la actualidad. No es casual que en las conclusiones de este escrito se registre un fenómeno tan doloroso como puede ser el de la desaparición de miles de personas a manos de una violencia abierta y soterrada: la hostilidad y el dolor de las víctimas resquebraja todo optimismo en una tierra devastada.

\section{LA HOSTILIDAD HACIA LA VIDA}

En la relación del individuo con el cuerpo, tanto con el propio como con el ajeno, vuelven la irracionalidad y la injusticia en forma de crueldad, que está tan lejos de la relación inteligente, de la reflexión feliz, como el dominio lo está de la libertad. Esto ha sido reconocido en todo su alcance en la teoría nietzscheana de la crueldad y mucho más en Sade, y ha sido interpretado psicológicamente por Freud en sus teorías sobre el narcisismo y sobre el instinto de muerte (Adorno y Horkheimer, 1998, p. 278).

En Dialéctica de la llustración, Adorno y Horkheimer identificaron con suma suspicacia el plano de una existencia silenciada - pero a la vez determinante en la fundación del tipo de realidad que emergió con la época moderna- que se refiere al sojuzgamiento de las personas. Es un hecho que al interior de las esferas de poder se mostró claramente un interés por el cuerpo que resultaría paradigmático y definitivo, ya que, en su individualidad, considerado como sujeto autónomo, el ser humano muy pronto se convirtió en el elemento central de la autocomprensión normativa de la sociedad y no sólo en una máquina de producción. El objetivo del examen emprendido por los pensadores de la Escuela de Frankfurt se dirigió a sacar a luz la relación conflictiva entre individuo y sociedad, ensamblando en una perspectiva filosófica los resultados de las investigaciones en psicología y sociología que a la sazón apuntalaban una serie de elementos comprensivos y no meramente descriptivos de la realidad estudiada. Para Adorno era primordial emprender una revisión del concepto de individuo debido a que constituía un punto de fuga en la teoría de la sociedad (Müller-Doohm, 2003, p. 581) y, en consecuencia, el problema de la individualidad resultó relevante para la comprensión de la realidad contemporánea en un doble aspecto. Por un lado, el tratamiento del tema comporta un sentido normativo, pues designa al sujeto que actúa por la autodeterminación de su voluntad; por otra parte, lleva consigo un elemento descriptivo, porque el concepto se emplea además para dar cuenta del cambio social efectuado desde el inicio del siglo XX, cuando la explotación de la riqueza se diversificó a tal punto que nada quedaría fuera de su interés. La conciencia de la complejidad de los procesos que dieron lugar a la Modernidad se explicita en Dialéctica de la llustración, al mostrar la historia oculta de la sociedad contemporánea que ha hecho de la destructividad racional el rasgo que la distingue de otras formaciones sociales:

Por debajo de la historia conocida de Europa corre una historia subterránea. Es la historia de la suerte de los instintos y las pasiones humanas reprimidos o desfigurados por la civilización. Desde la perspectiva del presente fascista, en el que lo que estaba escondido surge a la luz, también la historia manifiesta y conocida aparece en su relación con aquel lado oscuro, que ha sido descuidado tanto por la leyenda oficial de los Estados nacionales como por su crítica progresista (Adorno 
y Horkheimer, 1998, p. 277).

A través de estos acercamientos a la condición humana en sus diferentes planos — que desde el nacimiento del industrialismo hasta el día de hoy vive los efectos de las nuevas estructuras de dominación-, se han podido contrastar los tópicos del pensamiento moderno con el contemporáneo y trazar una demarcación que diferencia un periodo de otro. Al concluir el siglo XIX se observa el encomio de la energía individual y la vitalidad frente al nihilismo; el impulso a la secularización de la educación y la consiguiente crítica a la religión; la diatriba contra la moral de renuncia y el conformismo propios de la decadencia decimonónica; el cuestionamiento a toda concepción trascendente y metafísica en aras de una cientificidad volcada sobre los hechos y, en el plano económico, el elogio de la productividad y la riqueza de las naciones, entre otros aspectos. Cabe aclarar que además de estos señalamientos contra la caducidad de añejos principios que no responden más al tejido social y a la existencia personal, con el fin de la Modernidad se prendieron las alertas respecto a la creciente banalización de la vida y la indiferencia por las condiciones de miseria que surgen en las ciudades, opulentos centros industriales que marcaron la pauta del escepticismo en las sociedades del siglo XX.

Los nuevos tiempos inician con la noticia de la muerte de Dios, se abren las cerraduras que contenían de alguna manera todos esos rasgos de agresividad reprimidos; el deceso de la autoridad suprema pronto se convirtió en rumor que se propagó a gran velocidad y sobrevino la fractura de los valores suprasensibles hasta entonces venerados; cayeron los principios que tutelaron la existencia humana y habían sujetado o, al menos, representado un cierto freno a la obliteración de la vida individual en sus más íntimos reductos. Si con el materialismo característico del siglo XVIII la espiritualidad empezó a cerrar sus puertas, a la postre la corporalidad vino a reclamar, con legítimo derecho, la carta de ciudadanía para representar todo lo humano que determina la existencia, desprovista ya del encubrimiento sutil de una entelequia celestial. A partir de esta lógica, la secularización de la realidad permitió reconocer una vía de acceso a la nueva configuración del poder para una realidad emergente: si no hay un horizonte trascendente que dé significación al periplo terrenal de los seres humanos, vale más que éstos se vayan acostumbrando a la pesadez de su cuerpo.

A tal sentido de realidad que pone en el centro de la reflexión la terrenalidad y nivel ontológico del ser humano, le corresponde un tipo de saber que, como nunca, se ha estructurado a partir de su ensamblaje con la riqueza y el incremento de poder. Novedosas prácticas sociales de control y vigilancia aparecieron como las características de una sociedad y un modelo económico que han depurado las condiciones de explotación. Con este impulso, desprovisto ya del ropaje misterioso y beatífico, se construye ahora un saber valorativo del ser humano y de su individualidad, un saber que resulta de la observación y clasificación minuciosa de su comportamiento, de la evidente plasticidad de su constitución, del potencial creativo y productivo que le caracteriza, del examen detallado de su vida política y moral, así como de su fehaciente vulnerabilidad somática. Todo ello en función de la explotación laboral y de un discurso que estructura las esferas de saber que lo mismo construyen sujetos, objetos, conceptos, técnicas, conocimientos o prácticas diversas en el entramado de la existencia terrenal, acorralada como nunca y con menos puntos de fuga hacia la libertad. La morada del hombre es apenas un refugio en el único de los mundos posibles, que sin ambages se presenta caracterizado por la fuerza de gravedad de un pesimismo histórico.

Paralelamente a esta secularización, a principios del siglo XX, en el plano del discurso filosófico, la subjetividad seguía representando la apertura a una consideración crítica y reflexiva de la existencia, la cual tenía a su vez, en el predominio del materialismo y en el aprecio por la vida mundana, los ideales que hicieron de la explicación racional el emplazamiento (todavía) emancipatorio que la investigación necesitaba en la constitución de sujetos autónomos que, a pesar de la opresión, pudieran ser capaces de identificar su circunstancia gracias a la capacidad dinámica de su subjetividad. Aunque dicha oportunidad se presentaba sólo a condición de vislumbrar, en un amplio espectro, la forma en que el poder se ejerce tanto al nivel de las instituciones como de la vida privada, con lo que se abría un horizonte de investigación que hasta entonces apenas había sido barruntado por la filosofía política. El primer acercamiento en esta dirección pudo lograrse al dilucidar que se está frente a un tipo de ministerio anónimo y funcional, a menudo inaprehensible, difuminado en los pliegues más recónditos de la realidad social y en el flujo cotidiano de la existencia individual. Se trata de un sistema que ha creado conocimientos y técnicas para diferentes capas de realidad, que concibe campos de objetividad y los hace emerger hasta convertirlos en sistemas de sujeción soterrados, pero a la vez abiertos; grilletes que se muestran por igual en el ejercicio de la más devastadora saña y en la persuasión cínica y desfachatada, diseñada para adoptar y consumir estilos de vida aparentemente inocuos, aunque tan letales, como pueden ser la violencia y el sufrimiento 
expuestos sin eufemismos. Ese es el rostro del poder que ya se avizora.

En la lectura que hace la ontología del presente en torno a esta violenta deriva civilizatoria, aparece entre la bruma uno de esos rumbos en que se conjugaron coacción y seducción, que se vuelca sobre la relación amor-odio hacia el cuerpo, insoslayable relación que marca a profundidad toda la llamada civilización moderna, desde el trabajo incipiente de los gremios que germinaron en los burgos, hasta llegar al capitalismo imperialista que muestra sin pudor el terror acumulado de siglos de sometimiento. En la teoría crítica se encuentran esbozos que dilucidan las aristas de ese lugar central que la opresión va a tener desde los albores de la Modernidad, teñida con la sangre del odio y el amor hacia el cuerpo:

\begin{abstract}
El cuerpo, como lo inferior y sometido, es convertido de nuevo en objeto de burla y rechazo, y a la vez es deseado como lo prohibido, reificado, alienado. Sólo la civilización conoce el cuerpo como una cosa que se puede poseer, sólo en la civilización se ha distinguido y separado el cuerpo del espíritu — quintaesencia del poder y del mando- como objeto, cosa muerta, corpus. En la autodegradación del hombre a la categoría de corpus se venga la naturaleza del hecho de haber sido degradada y reducida por el hombre a objeto de dominio, a materia prima (Adorno y Horkheimer, 1998, p. 278).
\end{abstract}

En el sondeo dialéctico sobre la razón ilustrada, las estructuras de dominación corren paralelas a los procesos civilizatorios y, por más que se intente, no pueden obviarse las limitaciones de la racionalidad que ofreció progreso y lo cumplió, pero trajo consigo nuevas oleadas de barbarie (Benjamin, 1994, p.182). Sin embargo, la acometida contra el prestigio de la racionalidad moderna y frente a las consecuencias del dominio instrumental de ahí emanado, tuvo como respuesta en la posguerra el olvido oportunista y el engaño por parte de políticos, académicos e intelectuales cobijados por el manto del régimen, quienes - a despecho de lo que podría esperarse de una sociedad que vivió en carne propia el terror de la destructividad- prefirieron hundir en el pantano de la indiferencia el oscuro legado del autoritarismo. Pero si el monstruo que habitaba la casa propia era finalmente el enemigo encubierto, cuyo rastro se había borrado de la memoria, el trabajo de la filosofía consistió en subrayar la quimera de ese olvido y se propuso hacer que la investigación gravitase en torno al sufrimiento como condición de toda verdad. La marginalidad de su pensamiento hace que la teoría crítica siga siendo una filosofía del presente, ya que colige el espectro impersonal del poder que tiene una regencia a la vez subterránea y deletérea, que ha logrado consumar la despersonalización del individuo. La teoría crítica de la sociedad pone a la vista, y de forma muy clara, ese estado que mezcla la abulia y el ansia de novedades con la apatía y el completo anonimato de un ser sin perspectivas de realización personal porque ha caído en la ecuación del negocioconsumo, imperio que invade los más recónditos recintos de la personalidad. Esta situación tiene una clave que la explica: la profunda escisión de la personalidad ha traído como secuela una marcada hostilidad hacia la vida.

El germen de esta discordia anida en distintos sectores: en las clases oprimidas, que sólo conocen y han experimentado en el decurso de su existencia una vida dañada, de modo que la hostilidad produce reacciones violentas que llegan al homicidio y que, a diferencia de lo que una lectura edificante y sancionadora haría respecto al daño social que ocasiona el homicida, este hecho deleznable ha sido un instrumento fundamental para gobernar. Ese odio acumulado hacia la vida que crece en el corazón de los seres esclavizados se transforma en una siniestra fuerza de inagotable sujeción dentro de un ámbito que los frankfurtianos llamaron "la esfera nocturna de la historia" (Adorno y Horkheimer, 1998, p. 280). En Dialéctica de la llustración se enfatizan diversos talantes que, si bien representarían lo opuesto al homicidio, son igualmente expresiones de la hostilidad hacia la vida, tal es el caso del puritanismo. En esta dirección, cabe advertir que no sólo en la parte oprimida anida tal antipatía, los opresores dan también rienda suelta a dicha relación destructiva con actitudes y acciones que pasarían por ser algo a favor de la vida, pero que encubren ese resentimiento identificable en distintos momentos. Así, la propaganda fascista que hace ondear como su mayor presea el amor a la naturaleza y al destino, lleva oculto el componente reactivo que se solaza en la sumisión del cuerpo con la paulatina degradación de la vida.

Aún más, frente al autoritarismo se destaca otra postura de brutalidad y sometimiento que, en apariencia contradictoria, revela esos renglones torcidos de la personalidad que exalta al cuerpo en el ejercicio y la demostración de fortaleza, y tiene a la vez una marcada propensión al asesinato, el mismo rasgo de los cazadores que dicen amar la naturaleza. Con estos aspectos se delinea la relación ambivalente que el 
poder ejerce en el mundo contemporáneo: las interpretaciones sobre la vida y la muerte, junto con sus discursos y figuras ilustrativas, contienen un matiz que carga las contradicciones entre libertad y represión del cuerpo.

En la civilización occidental, y probablemente en todas, el cuerpo es tabú, objeto de atracción y de repugnancia. En los señores de Grecia y en la época feudal la relación con el cuerpo se hallaba aún determinada y condicionada por la agilidad de respuesta personal, que era condición de su dominio. El cuidado del cuerpo poseía, ingenuamente, un fin social. El kalós kagathós, el hombre de bien, era sólo en parte apariencia; en parte, el gimnasio era efectivamente necesario para la conservación del propio poder, por lo menos como adiestramiento para una actitud señorial. Con el pleno traspaso del dominio a la forma burguesa, mediatizada por el comercio y el tráfico, y más aún con la industria, se produce una mutación formal. La humanidad se deja dominar, en lugar de por la espada, por el aparato gigantesco, que al final vuelve una vez más a forjar la espada. Así desapareció el sentido racional de la exaltación del cuerpo viril; los intentos románticos de una revalorización del cuerpo en los siglos XIX y XX no hacen más que idealizar algo muerto y mutilado (Adorno y Horkheimer, 1998, p. 278).

En semejante relación escatológica y beatífica, a cada momento se muestra el absurdo y la esquizofrenia de la actual sociedad, que ha engendrado infinidad de seres humanos torcidos por la crueldad que en un mismo acto mezclan sexualidad y homicidio, que pisan la corteza terrestre ensañándose sobre la víctima en turno, dispuesta ahí para ser despedazada bajo la disciplina del todo social a la que ceden como autómatas. Pero ¿cómo esperar el surgimiento de personas libres o virtuosas en medio de un sistema que fomenta el más acendrado individualismo? ¿Los seres dantescos que matan a sus hijos y esposas, a sus padres y hermanos, que ultrajan a la mujer que tiene la desventura de cruzarse en su camino, son los únicos culpables o responsables de sus actos deleznables? Por lo que puede observarse en el transcurrir cotidiano, estamos muy lejos de haber arribado al tipo de sociedad que produciría humanos con otro carácter, con una conciencia distinta que no fuese el crisol de la podredumbre que hoy rodea a la sociedad. Evidentemente hay una especie de imperio heterónomo sobre los actos que conduce al abismo de la abyección, y esto no puede ser descartado apelando tan sólo a una dimensión política que, como arena de los debates, resolvería cualquier controversia llamando a la conciliación. El problema es tanto más profundo en la medida en que ha calado hasta el límite magmático de la existencia humana. Las palabras con que termina la Dialéctica de la Ilustración no podrían ser más pesimistas. No obstante, la Teoría crítica no es una profesión de fe sobre el desaliento, su pesimismo es histórico, no moral ni existencial:

\begin{abstract}
La buena voluntad se vuelve mala a causa de la violencia sufrida. Y no sólo la pregunta prohibida, sino también la imitación, el llanto o el juego temerario prohibidos pueden producir estas cicatrices. Como las especies de la serie animal, también los niveles intelectuales dentro del género humano, e incluso los puntos ciegos en un mismo individuo, señalan las estaciones en las que la esperanza se detuvo y son testimonio, en su petrificación, de que todo lo que vive está bajo una condena (Adorno y Horkheimer, 1998, p. 303).
\end{abstract}

Frente a la crisis civilizatoria, la reflexión de Theodor W. Adorno propone el concepto de mímesis, mismo que reivindica naturaleza y cuerpo por el valor que representan, y lo hace a contracorriente de la mediatización provocada por el tráfico mercantil y la explotación de la fuerza de trabajo. Así, el cuerpo no tendría que ser el precio que se tiene que pagar a cambio de la felicidad añorada, sino que la naturaleza y el cuerpo serían el principio que hace posible y deseable una real propuesta emancipatoria que no renuncia a la felicidad, que construye comunidad sin tener que sacrificar la propia individualidad y que concibe la existencia en un horizonte que asimila la idea de una sociedad libre de cualquier clase de crueldad o resentimiento, un tipo de relación que no se basa en el sojuzgamiento, sino en la paz, en la identificación y empatía no sólo con la dimensión humana, sino con la propia naturaleza sometida también al criterio de rentabilidad.

La teoría crítica define el tono en que se articula su lenguaje y, con la claridad que le da un pensamiento exento de cualquier complacencia, su posición filosófica da cuenta de los mecanismos ideológicos de integración que aniquilan aquello que es distinto, que escapa a la lógica de la identidad y se resiste a la fuerza que todo lo iguala en su afán por eliminar lo individual y no-idéntico. Mas habría que decir que su 
apuesta no se decanta a favor de un individualismo narcisista, por el contrario, la reflexión que parte de una experiencia individual se propone conocer, a través de esta experiencia personal, lo general, los sedimentos de una realidad social e histórica en la cual el individuo está inmerso. Si la experiencia y el sufrimiento se conciben como pertenecientes al plano individual, son asimismo expresión de los conflictos no resueltos que subyacen en los oscuros sótanos de la sociedad. Evitando caer en la sujeción que ha penetrado los discursos hegemónicos característicos de la racionalidad ilustrada, la criba que la Escuela de Frankfurt propone se articula en la tensión entre experiencia y utopía que, sin renunciar al pensamiento racional, no declara en tono afirmativo o edificante sus anhelos o convicciones, sino que describe y contempla la realidad social desde una perspectiva de contraste con aquello que sería posible y deseable, teniendo en cuenta las más sutiles formas de coacción que han marcado el devenir histórico de las modernas sociedades y su extravío hacia los Estados totalitarios. La tentativa de explicación de esta deriva histórica en la que el ser humano tiende a identificarse con el poder que lo domina, tiene que plantearse bajo la mira de enfoques distintos para tratar de comprender por qué, en un momento de la historia en que gracias al desarrollo tecnológico y científico sería dable para la humanidad alcanzar la emancipación, lo que se origina es la destrucción racionalmente conducida, pero bellamente presentada en el mercado de los bienes de consumo.

Con el advenimiento del capitalismo todo se transforma en medio y, lo que debería ser un medio, el dinero, se transforma, a su vez, en fin. La inversión así experimentada es el fetichismo de la mercancía, que sacrifica al individuo y sus necesidades más apremiantes a reglas y necesidades comercializables. El análisis económico y político se ve complementado por los estudios culturales para elaborar el diagnóstico de ese gigantesco mercado diseñado para el consumismo; incluso en el lado amable de la creatividad puesta al servicio del comercio, hay una violencia que rompe la unidad vital del cuerpo y lo dispone para su abierta compraventa.

Los artistas han preparado para la publicidad, sin quererlo, la imagen perdida de la unidad de alma y cuerpo. La exaltación de los fenómenos vitales, desde la bestia rubia hasta el isleño de los mares del Sur, desemboca inevitablemente en la película "exótica", en los carteles publicitarios de las vitaminas y de las cremas de belleza, que sólo son los lugartenientes del fin inmanente de la publicidad, del nuevo, grande y noble tipo humano: los jefes y sus tropas (Adorno y Horkheimer, 1998, p. 279).

La civilización ha podido enarbolar sus victorias mediante un proceso que conjuga el amor y el odio hacia la naturaleza y el cuerpo, su mayor conquista reside en la sublimación de la fuerza agreste que ha logrado separar a los hombres. El poder alcanza una nueva cima, ha consumado el caudillaje subliminal a través de la venta de estilos de vida que detrás del rostro agradable oculta la rudeza devastadora, utilizando todos los medios a su alcance en acciones brutales y sutiles.

Pero el asesino, el sicario, los gigantes embrutecidos, que son utilizados secretamente como verdugos por los poderosos, legales e ilegales, grandes y pequeños; los seres brutales que están siempre a disposición cuando se trata de liquidar a alguien, los linchadores y miembros del clan, el tipo forzudo que se levanta cuando alguien abre el pico, los tremendos personajes a los que cada uno queda siempre abandonado apenas se aparta de él la mano protectora del poder, apenas pierde dinero y posición; todos los ogros que viven en la oscuridad de la historia y mantienen despierto el miedo sin el cual no existiría dominio alguno: en ellos, el odio-amor hacia el cuerpo es brutal e inmediato; ellos violan todo lo que tocan, destruyen lo que ven a la luz, y esta destrucción es el rencor por la reificación; todos ellos repiten con ciego furor sobre el objeto viviente lo que no pueden impedir que haya acontecido: la escisión de la vida en espíritu y en su objeto (Adorno y Horkheimer, 1998, p. 279).

La escisión de la vida marcó la pauta del poder impersonal, que registra un vertiginoso ascenso en la medida en que el sistema se retroalimenta en su propia acción de consumir lo que produce, de este modo encuentra su mayor legitimación en las diversas acciones que respaldan el orden que mantiene al sistema en su autoorganización multidimensional. El holocausto no representa otra cosa que el excedente sacrificial de la Segunda Guerra Mundial. No fue gratuito que la reflexión sobre el poder se hubiera 
convertido en el eje que concentra la actividad crítica del pensamiento filosófico a partir de la segunda mitad del siglo XX, ya que su influjo no sólo se ha adueñado de las instituciones y ámbitos gubernamentales que rigen el entorno social, sino que ha estructurado estrategias de dominación que han consumado el dominio biológico tanto del individuo aislado como de la especie entera. Bajo el capitalismo, el engendro de lo que Foucault Ilamó "biopoder" ha salido del cascarón, celosamente guardado en la incubadora, sintetizado en el laboratorio o protegido de las inclemencias del tiempo en el invernadero, su crecimiento y diversificación son innegables. El biopoder se convirtió en el procedimiento sutilmente consumado de maniatar a individuos y dominar el mundo.

El individuo, la familia, el clan, la raza, el linaje, la casta, la estirpe, el género, la especie, el pueblo, la tribu, la horda, la sangre, la cepa, la rama y la casa son apenas ecos o vestigios de los que se vale una fuerza que aglutina significados y marca el futuro de las generaciones venideras, las mismas que están contempladas en los estudios de mercado de todas las industrias dedicadas a los cuidados prenatales y a producir lo que los padres y sus crías requieren. La prospectiva de estas empresas las lleva a cotizar con éxito en la bolsa de valores comprando futuro, diseñando la mercadotecnia para tener disponibles los productos idóneos para generaciones que nacerán dentro de diez o veinte años, pero que ya quedan cercadas por la red de consumo que se ha apropiado de su vida mucho antes de que sean una realidad encarnada en personas concretas. El biopoder es este despotismo performativo que quebranta la libertad.

Al hilo de estas disquisiciones ensambladas en el tejido del pensamiento filosófico, aparece una pregunta que no se puede soslayar: ¿se puede mantener vigente la esperanza de una sociedad que permita la reconciliación de sus necesidades e intereses con las expectativas del individuo? Si el poder ocupa todos los resquicios y no deja abierta la posibilidad de una experiencia no mediada, la idea de una subjetividad que vislumbra los diferentes flancos en que se ejerce el dominio es ya la esperanza que daría cabida a una sociedad sin antagonismos irreconciliables. La subjetividad crítica permite pensar que aún quedan intersticios para una vida libre, que aún puede vislumbrarse en el horizonte un lugar en el que la vida deje de ser el lento suicidarse de todos (Nietzsche, 1983, pp. 87-88). La clave para tal convencimiento radica en el vínculo entre Eros y Thanatos, a partir de ahí podría determinarse si es probable una civilización no represiva (Marcuse, 1983, p. 203).

\section{EL ÁRBOL DEL CONOCIMIIENTO}

Como punto de partida cabe decir que quizá ninguna teoría sobre la estructura de la mente ha ejercido una influencia tan determinante como lo ha hecho el psicoanálisis, cuyas explicaciones y categorías básicas inobjetablemente han contribuido de manera radical a la construcción de un modo inédito de entender las relaciones entre la vida psíquica y la realidad social. Pero Freud no escribe ni crea una teoría a partir de la nada. La época moderna, desde su más temprano albor, ha marcado su interés radical por la vida interior del individuo, mas no sólo como tema de diálogo o elucubración, sino como exploración de la pisque propia y trabajo de autorreflexión que alza el vuelo desde amaneceres mucho más remotos, los cuales son identificables en la obra de San Agustín o de Petrarca, hombres impulsivos y sedientos de explicaciones que abrevan en la fuente del estoicismo y dan cuenta de una interioridad que en el ser humano está sitiada por el infortunio y por las tentaciones de todo tipo, por el afán de hegemonía, la agresión y el choque de las vidas individuales en el seno de la dialéctica entre el amo y el esclavo en donde uno impone y el otro tolera las reglas que rigen fenómenos como la sexualidad.

El trabajo psicoanalítico nos ha enseñado que son justamente esas frustraciones [denegaciones] de la vida sexual lo que los individuos llamados neuróticos no toleran. Ellos se crean, en sus síntomas, satisfacciones sustitutivas, que, empero, los hacen padecer por sí mismas o devienen fuentes de sufrimiento por depararles dificultades con el medio circundante y la sociedad. Lo segundo se comprende con facilidad; lo primero nos pone frente a un nuevo enigma. Ahora bien, la cultura exige otros sacrificios, además del de la satisfacción sexual (Freud, 1980, p. 72).

En esta confrontación, que tiene como escenarios la cultura y el campo labrado por los distintos procesos civilizatorios, se han ido construyendo principios y direcciones que guían tanto el libre albedrío como la dominación ideológica, la fortaleza militar, el usufructo de la fuerza y la coerción jurídica. Ahora bien, si se toma como base la idea marxista de que la raíz del hombre es el hombre mismo, después de columbrar la base real de la sociedad en el plano material de la producción y de elaborar un diagnóstico de decadencia 
de la cultura que engendra nuevas formas de barbarie y explotación, el paso siguiente fue el dictamen acerca de la vida anímica preparado por siglos de introspección. El individuo se vio contrapuesto al bien más valioso, definido bajo el polisémico rótulo de cultura aderezado con brillantes recompensas y no menos férreas cadenas. La alternativa estuvo siempre enclavada en medio del concepto irrestricto de libertad y la necesaria domesticación, disyuntiva que, en sus vaivenes, trae al individuo entre el egoísmo propio de su individuación y el respeto a los límites impuestos por el orden moral y la esfera jurídica. La pregunta fundamental fue entonces determinar si acaso sería posible vislumbrar y erigir un tipo de sociedad en la que se pudiera armonizar el egoísmo pulsional y la paz social; una sociedad racional y libre a la vez, de normas y principios que garantizan la seguridad y los cauces para la expresividad redimida. Así lo enuncia Freud:

Muy bien podríamos imaginar una comunidad culta compuesta de tales individuos dobles, que, libidinalmente saciados en sí mismos, se enlazaran entre ellos a través de la comunidad de intereses y de trabajo. En tal caso, la cultura no necesitaría sustraer energía a la sexualidad. Pero ese deseable estado no existe ni ha existido nunca; la realidad efectiva nos muestra que la cultura nunca se conforma con las ligazones que se le han concedido hasta un momento dado, que pretende ligar entre sí a los miembros de la comunidad también libidinalmente, que se vale de todos los medios y promueve todos los caminos para establecer fuertes identificaciones entre ellos, moviliza en la máxima proporción una libido de meta inhibida a fin de fortalecer los lazos comunitarios mediante vínculos de amistad. Para cumplir estos propósitos es inevitable limitar la vida sexual. Pero aún no inteligimos la necesidad objetiva que esfuerza a la cultura por este camino y funda su oposición a la sexualidad. Ha de tratarse de un factor perturbador que todavía no hemos descubierto (Freud, 1980, p. 73).

Llegamos aquí a una formulación hipotética, en la que ese factor perturbador no descubierto aún por Freud empieza a plantearse en las palabras que dan cuerpo a La voluntad de saber de Foucault, en donde el autor propone que la sexualidad bien puede ser considerada como una dimensión de un dispositivo histórico de sujeción que ha puesto al sexo en una plataforma discursiva. Si hasta entonces la sexualidad había sido explicada apelando a una condición natural, Foucault insinúa que los rasgos "naturales" de la sexualidad se deben a los caracteres de los discursos que hablan sobre el sexo y, si el saber sobre la sexualidad ha configurado un objeto de estudio con estos rasgos, lo hace en función de las relaciones que lo entrelazan con el poder. La sexualidad es el nombre que las ciencias humanas han dado a un dispositivo histórico que, según Foucault, inicia en un contexto específico:

Siglo XVII: sería el comienzo de una edad de represión, propia de las sociedades llamadas burguesas, y de la que quizá todavía no estaríamos completamente liberados. A partir de ese momento, nombrar el sexo se habría tornado más difícil y costoso. Como si para dominarlo en lo real hubiese sido necesario primero reducirlo en el campo del lenguaje, controlar su libre circulación en el discurso, expulsarlo de lo que se dice y apagar las palabras que lo hacen presente con demasiado vigor. Y aparentemente esas mismas prohibiciones tendrían miedo de nombrarlo. Sin tener siquiera que decirlo, el pudor moderno obtendría que no se lo mencione merced al solo juego de prohibiciones que se remiten las unas a las otras: mutismos que imponen el silencio a fuerza de callarse. Censura (Foucault, 1976, p. 25).

La crítica a una sociedad que se distingue por su hipocresía tiene en la sexualidad el punto de articulación para una doble moral, la censura castrante por un lado, y la perversión inducida que mercantiliza el cuerpo por el otro. Hay un amplio espectro de placeres culposos que entran en la economía de los discursos y facturan formas de vida caracterizadas por la degradación. Se tiene aquí un claro ejemplo de análisis discursivo que remite a la formación de una experiencia determinada y sus respectivas formas de comprensión en el marco del saber de una época que se ha ido perfeccionado con el progreso de la civilización. En el Nacimiento de la biopolítica, que engloba una serie de cursos impartidos entre 1978 y 1979 en el Colegio de Francia, Foucault expone la metamorfosis señalada. 
de tal modo que el Estado pueda llegar a ser sólido y permanente, que pueda llegar a ser fuerte frente a todo lo que amenaza con destruirlo (Foucault, 2007, p. 19).

La profundidad que es factible reconocer en este trabajo reflexivo no se limita a poner en evidencia la serie de costumbres, valores o ideas que han interiorizado los individuos, sino que su propuesta atiende de manera fundamental a las formas en que son subjetivadas las relaciones sociales e interpersonales en una red difusa de relaciones de poder. El carácter social de tales relaciones las hace ineludibles para el individuo, puesto que van dirigidas a su condición corporal y le interpelan directamente; por lo tanto, le es imposible sustraerse a su influencia, pues el cuerpo determina el rol de su comportamiento y las formas de relación con los demás. Si el poder vigila y controla el cuerpo, lo hace porque está inmerso en todas las actividades que realiza el ser humano, quien en su actuar cotidiano reproduce y dimensiona ámbitos cada vez más vastos de relaciones instauradas por el sistema. Para percibir el tipo de relaciones que se llevan a cabo en el sistema de dominio, la investigación filosófica tiene que efectuar una interpretación cabal de sus instantes formativos y emprender la descripción de las variaciones que han sobrevenido con el paso de una sociedad disciplinaria, cuyos elementos en juego resultan en mayor o menor medida identificables, hasta arribar a una sociedad de control como la que el día de hoy se vive, caracterizada por una sumisión difusa que con desparpajo bordea los límites de lo placentero y lo horroroso.

Las subjetividades se configuran en cada época según el poder que legitima o sanciona los juegos de verdad o falsedad por medio de los cuales los individuos van construyendo su historia en la confluencia de vivencias, ideologías y condicionamientos que intervienen para que el poder se materialice, sea como represión o permisividad. La reflexión sobre el horizonte de la sexualidad adquiere una relevancia inobjetable, ya que puede pensarse que el poder actúa tanto en un sentido represivo — según la época y el ensamble con el saber - o bien puede albergar ciertos rasgos de seducción y permisividad a tal grado que pueda plantearse un momento de creación en la sexualidad a partir de los rasgos de un nuevo discurso en un tiempo determinado, en el que la vida y el lenguaje se entrelazan. Para Deleuze, hay una clara yuxtaposición de dimensiones:

En la vida ya no sólo existe una fuerza de organización, sino planos de organización espacio-temporales, irreductibles entre sí, según los cuales los vivientes se diseminan [...] En el lenguaje ya no sólo existe una fuerza de flexión, sino planos según los cuales las lenguas afijas o en flexión se distribuyen, y en los que la suficiencia de las palabras y de las letras es sustituida por las interrelaciones sonoras; el lenguaje ya no se define por sus designaciones y significaciones, sino que remite a "voluntades colectivas" (Deleuze, 1987, p. 164).

Las fuerzas que concurren en la conformación del saber en la Modernidad han hecho de la sexualidad un factor determinante desde el siglo XVIII, en que se consolida la explicación científica del mundo e invade los más variados escenarios sociales. Como dispositivo, la sexualidad aglutina diferentes estrategias de saber y conjuga las más variadas tácticas para establecer controles precisos en los cuerpos individuales y en las poblaciones enteras, ligando un sinfín de prácticas opresivas o placenteras, pero siempre convirtiendo en coercitivas diversas relaciones sociales. Tal dispositivo de control produce y envuelve la misma sexualidad al naturalizarla, ocultando que sea creación y efecto del poder. Ahora se pregona la libertad de elegir la definición de la sexualidad propia, las consecuencias de esta proclama ya están haciendo eclosión. Empero, hay otro nivel de dominio brutal sobre los cuerpos que no tiene que ver con el supuesto de que hay cierto margen de elección para definir la sexualidad y la relación vital con el entorno. Este nivel es propio de una ciencia melancólica y se expone en el último apartado de este escrito.

\section{EL EXCEDENTE SACRIFICIAL}

Según estudios de impacto económico, el capitalismo está llegando a un punto de escasez natural por el ecocidio. No obstante, existe otra esfera aún más profunda, oculta, desgarradora, que se ha instalado en un país como México y ha hecho de la violencia sobre el cuerpo y la explotación sexual los ejes que han destruido la vida comunitaria.

Con tal afirmación se alude al drama vinculado con las innumerables víctimas de desapariciones forzadas, 
que el 30 de agosto de 2020, cuando se conmemora el día internacional de este fenómeno doloroso -difundido por Change.org México, para hacer un llamado a la sociedad a que deje la indiferencia-, se han revelado datos aproximados que dan cuenta de la magnitud del problema que viven las más de 75 mil personas desaparecidas, además de sus familiares y amigos. En su llamado a la solidaridad, Change. org México hace referencia a los informes de la Secretaría de Gobernación: desde 1964 se han reportado alrededor de 177863 desapariciones en México, de las cuales permanecen en este estado más de 75092. A partir del inicio de la administración de Andrés Manuel López Obrador, se han denunciado alrededor de 63 mil desapariciones. El subsecretario de Gobernación, Ricardo Peralta Saucedo, señala que de diciembre de 2006 a julio de 2020 se tiene conocimiento de alrededor de 3978 fosas clandestinas en todo el país. Los estados con más fosas clandestinas son Veracruz, Sinaloa, Colima, Guerrero y Sonora. El 75 \% de las personas desaparecidas son jóvenes de entre 15 y 30 años. De este porcentaje, el $75 \%$ son hombres y el $35 \%$ son mujeres; destaca que la mayoría de los desaparecidos menores de 18 años son mujeres. De igual modo, el periódico La Jornada da cuenta del hecho:

De acuerdo con el registro nacional de personas desaparecidas y no localizadas de la Secretaría de Gobernación, hasta el 29 de agosto se reportaban 74 mil 848 casos. De ese total, denunció la Red por los Derechos de la Infancia en México, casi uno de cada cuatro son menores de edad, pues los números oficiales indican que 17 mil 312 (23.12 por ciento) tenían de cero a 17 años cuando no volvieron (Redacción, 2020).

Pero estos datos no son sólo un número más, cada uno refiere a miles de personas afectadas. Por ello, el Movimiento por Nuestros Desaparecidos en México creó una petición que ha unido a más de 133 mil personas desde hace un año, en donde se plantean las exigencias y los protocolos que las autoridades deben seguir para encontrar a los seres queridos (Campaña por nuestros desaparecidos \#LesQueremosdeVuelta).

Es claro que la conciencia colectiva demanda una vida distinta, en la que nadie debería tener miedo de no regresar y estar con familiares y amigos. Hoy más que nunca se vuelve indispensable la participación de la ciudadanía para llevar justicia a todas las personas afectadas. Según la apreciación de Change.org México, este dato de tantas personas desaparecidas puede responder a problemas graves como la trata de mujeres, los feminicidios y el abuso sexual. El dominio atroz que alimenta esa zona oscura del acaecer histórico es el problema más lacerante al que se ha enfrentado la teoría crítica, la maquinaria de muerte parece no tener límite. En este sentido, una sociedad distinta aún parece lejana, pero "La filosofía insiste en que las acciones y fines del hombre no deben ser producto de una ciega necesidad" (Horkheimer, 1998, p. 276). Sin embargo, en la actualidad el ser humano continúa su marcha al compás de lo que acaece en la esfera nocturna de la historia, caracterizada por la destrucción humana, el hambre, el tráfico de personas, la nueva esclavitud y la auto aniquilación.

\section{CONCLUSIÓN}

La sociedad actual se encuentra en medio de una agudizada crueldad, muerte y desaparición de personas. En la espiral de devastación que se ha generado, mucha gente está decepcionada de buscar que haya justicia sin encontrarla, porque la justicia viene de la lucha y no es fácil ganar. Sin embargo, la lucha es tan necesaria que no encuentra reposo, pues ésta no consiste tan sólo en argumentar y vencer en los debates teóricos; por el contrario, lo que se necesita es hablar de los temas que atraviesan la vida cotidiana y que amenazan con normalizar ese nivel creciente de destructividad. América Latina cuenta con una larga historia de violencia ejercida contra sus poblaciones; un fenómeno de varias décadas y de cientos de miles de desaparecidos, primero a manos de los escuadrones de la muerte en los regímenes militares y ahora a manos de los traficantes de personas. Esta genealogía de desapariciones integra innumerables casos no resueltos, ni por la justicia, ni por la dimensión emocional de las personas que siguen esperando a los suyos. ¿Cómo dar expresión a algo que no puede siquiera asimilarse? En cada persona sumida en este almarjal de tristeza, las arrugas del rostro exponen la profundidad de las lesiones. Con semejante experiencia una verdad salta a la vista: se ha asesinado el futuro cuando una sociedad mata a sus jóvenes o los desaparece ocultándolos bajo tierra en fosas clandestinas. Este hecho ha traído un alto costo de aprendizaje, definido por la creciente banalización de la vida y de la muerte.

En este momento resulta fundamental contar con voces independientes que estén siempre en alerta para 
que la aflicción no se instaure como si fuera lo habitual en el contexto de la lucha por la justicia. En este sentido, ¿qué se puede pensar acerca de algo tan opuesto a la violencia como es el perdón? En los tribunales a menudo se plantea como salida posible otorgar el perdón, mas en países con tantas atrocidades y atropellos, el perdón no significa olvidar, sino dar voz a todas las víctimas, porque las palabras de perdón no las puede decir una tercera persona, el perdón sólo puede suceder cuando ha habido justicia. No obstante, cabe recordar también que se trata de heridas que no cicatrizan.

En una investigación del tiempo presente, con frecuencia irrumpe un proceso en el que se entrelazan componentes estéticos y morales que configuran las tragedias contemporáneas, en las que parece haber un circuito entre lo nuevo y lo antiguo. La Teoría crítica busca un lenguaje para poder expresar lo esencial del ser humano como un individuo que vive y reconoce las circunstancias de opresión en que se encuentra, pero que sigue siendo capaz de cultivar la crítica para hacer posible aún la resistencia e imaginar su eventual emancipación. La importancia de este horizonte filosófico es que continúa siendo irreductible al orden performativo y esto hace de la Teoría crítica una reflexión actual, ya que encarna la posibilidad de un pensamiento negativo, de resistencia a la orientación homogénea de la lógica industrial de la destrucción y, sobre todo, porque en su perspectiva, la configuración actual de la realidad no representa un estado de cosas definitivo. La esperanza sigue siendo el impulso del pensamiento filosófico a pesar de los días aciagos que hoy se viven.

\section{REFERENCIAS}

Adorno, T. W. (1993). Consignas. Amorrortu.

Adorno, T. W., y Horkheimer, M. (1998). Dialéctica de la Ilustración. Trotta.

Benjamin, W. (1994). Discursos interrumpidos. Planeta-Agostini.

Movimiento por Nuestros Desaparecidos en México. (2020, agosto 20). Campaña por nuestros desparecidos \#LesQueremosdeVuelta. Change. Recuperada de https://cutt.ly/ohLEP1N

De la redacción (31 de agosto de 2020). Reprochan madres de desaparecidos inacción del gobierno. La Jornada. Recuperada de: https://www.jornada.com.mx/2020/08/31/politica/oo8n1pol

Deleuze, G. (1987). Foucault. Paidós.

Foucault, M. (1976). Historia de la sexualidad I. La voluntad de saber. Siglo XXI.

Foucault, M. (2007). Nacimiento de la biopolítica. Fondo de Cultura Económica.

Freud, S. (1980). El malestar en la cultura. Siglo XXI.

Horkheimer, M. (1998). Teoría crítica. Amorrortu.

Marcuse, H. (1981). El final de la utopía. Planeta/Ariel.

Marcuse, H. (1983). Eros y Civilización. Sarpe.

Mcbride, W. (2013). Las formas de la violencia en el mundo actual. Entre distintos tipos de violencia. Dialéctica, 45-46, 9-18.

Müller-Doohm, S. (2003). En tierra de nadie. Herder.

Negri, A. y Hardt, M. (2005). Imperio. Paidós.

Nietzsche, F. (1983). Así habló Zaratustra. Bruguera.

Salas, J. (2020, enero 24) Científicos adelantan el 'reloj del apocalipsis': quedan cien segundos para el fin del mundo. El País. Recuperada de: https://elpais.com/elpais/2020/01/23/ciencia/1579777464_692402.html

\section{AUTOR}

Javier Corona Fernández. Doctor en Filosofía Universidad Nacional Autónoma de México. Profesor Departamento de Filosofía Universidad de Guanajuato. Libros como autor: “Los usos de la dialéctica. El pensamiento filosófico de José Revueltas”, 2016. “Poder y subjetividad: emplazamientos para una reflexión sobre el presente”, 2019.

\section{Conflicto de intereses}

El autor informa ningún conflicto de interés posible.

Financiamiento

No existió asistencia financiera de partes externas al presente artículo.

Agradecimientos

$\mathrm{N} / \mathrm{A}$ 